\title{
Survey of centers performing cardiovascular magnetic resonance in pediatric and congenital heart disease: a report of the Society for Cardiovascular Magnetic Resonance
}

\author{
Sujatha Buddhe ${ }^{1^{*}} \mathbb{D}$, Brian D. Soriano ${ }^{1}$ and Andrew J. Powell ${ }^{2}$
}

\begin{abstract}
Background: There are few data on practice patterns and trends for cardiovascular magnetic resonance (CMR) in pediatric and congenital heart disease. The Society for Cardiovascular Magnetic Resonance (SCMR) sought to address this deficiency by performing an international survey of CMR centers.

Methods: Surveys consisting of 31 (2014) and 33 (2018) items were designed to collect data on the use of CMR for the evaluation of pediatric and congenital heart disease patients. They were sent to all SCMR members in 2014 and 2018. One response per center was collected.

Results: There were 93 centers that responded in 2014 and 83 in 2018. The results that follow show data from 2014 and 2018 separated by a dash. The median annual number of pediatric/congenital CMR cases per center was 183-209. The median number of scanners for CMR was 2-2 (range, 1-8) with 58-63\% using only $1.5 T$ scanners and $4-4 \%$ using only $3 T$ scanners. The mean number of attending/staff reading CMRs was 3.7-2.6; among them, 52-61\% were pediatric or adult cardiologists and $47-38 \%$ were pediatric or adult radiologists. The median annual case volume per attending was 54-86. The median number of technologists per center doing CMRs was 4-5. The median scanner time allocated for a non-sedated examination was 75-75 min (range, 45-120). Among the 21 centers responding to both surveys, the mean annual case volume increased from 320 in 2014 to 445 in 2018; 17 (81\%) of the centers had an increase in annual case volume. For this subgroup, the median attending/staff per center was 4 in both 2014 and 2018. The median scanner time allotted per study was unchanged at $90 \mathrm{~min}$. The mean time for an attending/staff physician to perform a typical CMR examination including reporting was 143-141 min.
\end{abstract}

Conclusion: These survey data provide a novel comprehensive view of CMR practice in pediatric and congenital heart disease. This information is useful for internal benchmarking, resource allocation, addressing practice variation, quality improvement initiatives, and identifying unmet needs.

Keywords: Cardiovascular magnetic resonance imaging, Pediatric heart disease, Congenital heart disease, Survey

*Correspondence: sujatha.buddhe@seattlechildrens.org

1 Division of Cardiology, Department of Pediatrics, University

of Washington School of Medicine and Seattle Children's Hospital, Seattle, WA, USA

Full list of author information is available at the end of the article

\section{Background}

The use of cardiovascular magnetic resonance (CMR) for the evaluation of pediatric and congenital heart disease continues to grow and evolve. The numerous indications for this patient group have been delineated by various professional societies [1-3]. These include a wide variety 
of congenital and acquired conditions as well as scenarios such as initial diagnosis, pre-interventional planning, and serial follow-up. In many centers, CMR is fully integrated into clinical care alongside other traditional imaging modalities such as echocardiography and invasive cardiac catheterization. Despite this clear maturation, there are few multicenter data that describe CMR practice patterns and temporal trends in pediatric and congenital heart disease. This may limit a center's ability to review their practices, evaluate their program, and identify unmet needs. Professional societies such as the American Society of Echocardiography and the American Academy of Pediatrics have periodically surveyed centers regarding several practice components to address resource allocation and provide benchmarks [4-11] .

Under the auspices of the Society for Cardiovascular Magnetic Resonance (SCMR), we performed an international survey of CMR centers/programs caring for patients with pediatric or congenital heart disease. The survey was performed in 2014 and again in 2018 to assess temporal trends.

\section{Methods}

A survey consisting of 31 items in 2014 and 33 items in 2018 was designed with input from members of the SCMR Pediatric and Congenital Heart Disease Section Steering Committee. All items from the 2014 survey were included in the 2018 survey. The surveys were sent to all SCMR members by email in 2014 and then in 2018 using SurveyMonkey (San Mateo, California, USA) and posted on the SCMR website and Twitter account. One response per center was requested and included. The 2018 survey is shown as Additional file 1. The items included description of the program/center; CMR patient volume and age distribution; center echocardiogram and cardiac surgical volumes; CMR scanner type; use of sedation, anesthesia, and breath-holding; physician number, specialty, and coread practices; technologist number; center accreditation status; physician presence during examinations; CMR scanning days per week; scanner time allotted for typical examinations; personnel performing post-processing; image analysis software used for chamber volume and blood flow; average time spent per examination by physicians; gadolinium-based contrast agents used; sequences performed and reported in clinical reports; and interest in participating in future surveys.

Data are reported as mean and standard deviation for normally distributed continuous variables, median and range for non-normally distributed continuous variables, and number and percentage for categorical variables. A subgroup analysis was performed for centers responding to both surveys. All statistical analyses were performed using SPSS (version 19.0, Statistical Package for the
Table 1 Survey centers by country

\begin{tabular}{|c|c|c|c|c|}
\hline \multirow[t]{2}{*}{ Country } & \multicolumn{2}{|c|}{2014} & \multicolumn{2}{|c|}{2018} \\
\hline & $\mathrm{N}$ & $\%$ & $\mathrm{~N}$ & $\%$ \\
\hline United States & 57 & 62.0 & 49 & 68.0 \\
\hline United Kingdom & 9 & 10.0 & 1 & 1.4 \\
\hline Brazil & 5 & 6.0 & 2 & 2.8 \\
\hline Canada & 4 & 4.0 & 2 & 2.8 \\
\hline Australia & 2 & 2.0 & 1 & 1.4 \\
\hline Colombia & 2 & 2.0 & 0 & 0 \\
\hline Germany & 2 & 2.0 & 2 & 2.8 \\
\hline Italy & 2 & 2.0 & 1 & 1.4 \\
\hline Belgium & 1 & 1.0 & 0 & 0 \\
\hline Finland & 1 & 1.0 & 0 & 0 \\
\hline Hong Kong SAR & 1 & 1.0 & 1 & 1 \\
\hline Mexico & 1 & 1.0 & 0 & 0 \\
\hline Poland & 1 & 1.0 & 0 & 0 \\
\hline Spain & 1 & 1.0 & 0 & 0 \\
\hline Sweden & 1 & 1.0 & 0 & 0 \\
\hline Switzerland & 1 & 1.0 & 0 & 0 \\
\hline Thailand & 1 & 1.0 & 0 & 0 \\
\hline The Netherlands & 1 & 1.0 & 0 & 0 \\
\hline Argentina & 0 & 0 & 1 & 1.4 \\
\hline Czech Republic & 0 & 0 & 1 & 1.4 \\
\hline Egypt & 0 & 0 & 1 & 1.4 \\
\hline France & 0 & 0 & 1 & 1.4 \\
\hline Greece & 0 & 0 & 1 & 1.4 \\
\hline Hungary & 0 & 0 & 1 & 1.4 \\
\hline Japan & 0 & 0 & 1 & 1.4 \\
\hline Kuwait & 0 & 0 & 1 & 1.4 \\
\hline Lebanon & 0 & 0 & 1 & 1.4 \\
\hline New Zealand & 0 & 0 & 1 & 1.4 \\
\hline Norway & 0 & 0 & 1 & 1.4 \\
\hline Romania & 0 & 0 & 1 & 1.4 \\
\hline Saudi Arabia & 0 & 0 & 1 & 1.4 \\
\hline
\end{tabular}

Social Sciences, International Business Machines, Inc., Armonk, New York, USA).

\section{Results}

A total of 93 centers responded in 2014 and 83 in 2018, including 21 centers that responded to both surveys. In the results that follow, values from 2014 to 2018 are separated by a dash. Nearly all centers (97-100\%) responded that they were interested in participating in future surveys.

\section{Center characteristics}

Table 1 shows the countries where the responding centers were located. The majority (62-68\%) of responders were located in the United States. Among all centers, 
40-43\% identified themselves as a free-standing or independent children's hospital; $27-31 \%$ as a children's hospital within a larger general hospital, and $27-19 \%$ as a general hospital where the majority of patients are adults (Fig. 1). Among centers in the United States, only American College of Radiology accreditation was obtained by 68-68\%, only Intersocietal Accreditation Commission Magnetic Resonance Imaging accreditation by $8-6 \%$, and both accreditations by $9-13 \%$.

\section{Patient volume and age}

The annual pediatric and congenital heart disease patient CMR case volume per center is shown in Fig. 2; the median was 183-209 cases. The annual pediatric and congenital heart disease patient echocardiogram case volume per center was $<5000$ in $32-28 \%, 5000$ to 10,000 in $32-28 \%, 10,000$ to 15,000 in $21-13 \%$, and $>15,000$ in $15-28 \%$. The annual pediatric and congenital heart disease surgery case volume per center was none in $13-11 \%$, $<250$ in $30-39 \%, 250$ to 500 in $38-26 \%$, and $>500$ in $19-24 \%$. Patients of all ages underwent CMR in $72-77 \%$ of the centers, only patients older than one year were scanned in $15-17 \%$ of the centers, only patients older than 18 years were scanned in $6-3 \%$ of the centers, and only patients younger than 18 years were scanned in $7-3 \%$ of the centers.

\section{Imaging technique}

The median number of scanners used for CMR per center was $2-2$ (range, $1-8$ ) and $66-78 \%$ used more than one scanner. The scanner manufacturer was Siemens in $51-49 \%$, Philips in $27-27 \%$, General Electric in $22-22 \%$, and Toshiba in $0-2 \%$. Among centers with more than one CMR scanner, $79-75 \%$ had a single scanner manufacturer. Regarding the CMR scanner field strength, only a $1.5 \mathrm{~T}$ scanner was used in $58-63 \%$ of the centers and

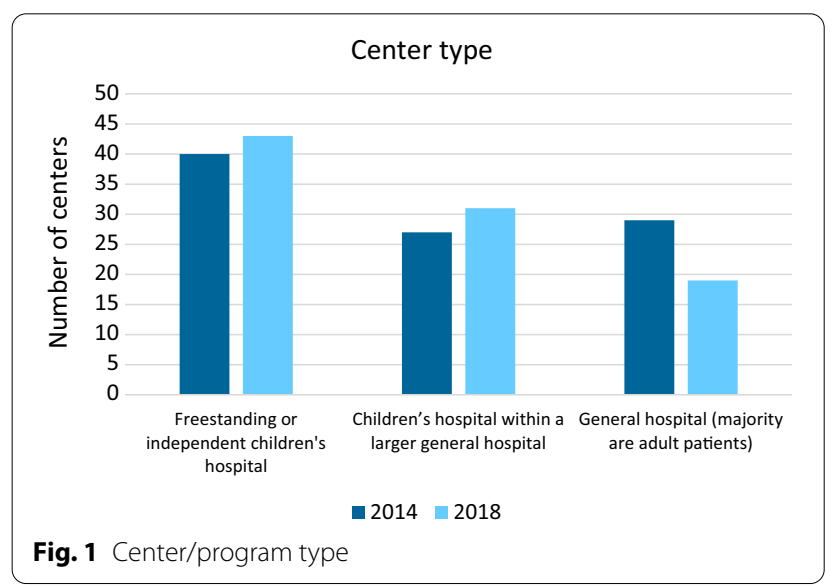

only a $3 \mathrm{~T}$ scanner was used in $4-4 \%$ of the centers; the remainder used both field strengths.

Sedation and/or anesthesia for some CMR cases was used in $84-86 \%$ of the centers. Among these centers, when using sedation and/or anesthesia, general anesthesia (defined as the use of endotracheal intubation or a laryngeal mask airway) was the predominant approach ( $>90 \%$ of cases) in $64-50 \%$ of centers, sedation without endotracheal intubation or a laryngeal mask airway was the predominant approach ( $>90 \%$ of cases) in $23-11 \%$ of centers, and a varied approach with either sedation or general anesthesia was used in the remaining $13-39 \%$ of the centers. For cases using general anesthesia, ventilation was intermittently suspended to decrease respiratory motion artifact in $\geq 50 \%$ of the cases at $64-52 \%$ of centers, ventilation was intermittently suspended to decrease respiratory motion artifact in $<50 \%$ of the cases at $16-33 \%$ of the centers, and ventilation was never suspended at $20-15 \%$ of centers.

Only the 2018 survey queried the type of gadoliniumbased contrast agent (GBCA). Only a macrocyclic GBCA was used in $79 \%$ of centers, only a linear GBCA was used in $12 \%$ of centers, and both types of GBCAs were used in $9 \%$ of centers. In 2014, 27\% of centers reported the use of gadofosveset (trade name Ablavar and Vasovist, Lantheus Medical Imaging, North Billerica, Massachusetts, USA). In 2018, this agent was no longer commercially available. In $2018,17 \%$ of all centers and $29 \%$ of centers in the United States used ferumoxytol (trade name Feraheme, AMAG Pharmaceuticals, Waltham, Massachusetts, USA) as a contrast agent. Among the centers that performed CMR examinations in patients $<30$ days of age, GBCAs were used in patients $<30$ days of age in $62-71 \%$.

In the 2018 survey, 38 centers responded to questions on the use of newer techniques. Among them, fourdimensional (4D) flow sequences were acquired by $55 \%$ of the centers and 4D flow data were included in the clinical report in $18 \%$ of the centers. T1 mapping sequences were performed by $97 \%$ of the centers and data from T1 mapping was included in the clinical report in $66 \%$ of the centers. Three-dimensional black-blood sequences were performed in $24 \%$ of the centers, feature tracking in $55 \%$ of the centers, tissue phase mapping in $18 \%$ of the centers, and compressed sensing in $32 \%$ of the centers.

\section{Staff}

The mean number of attending/staff who report pediatric/congenital CMR examinations per center was 3.7-2.6. The median case volume per attending/staff physician per year was 54-86. Among the attending/ staff physicians reporting pediatric/congenital CMR examinations, $52-61 \%$ were pediatric or adult cardiologists, $47-38 \%$ were pediatric or adult radiologists, 

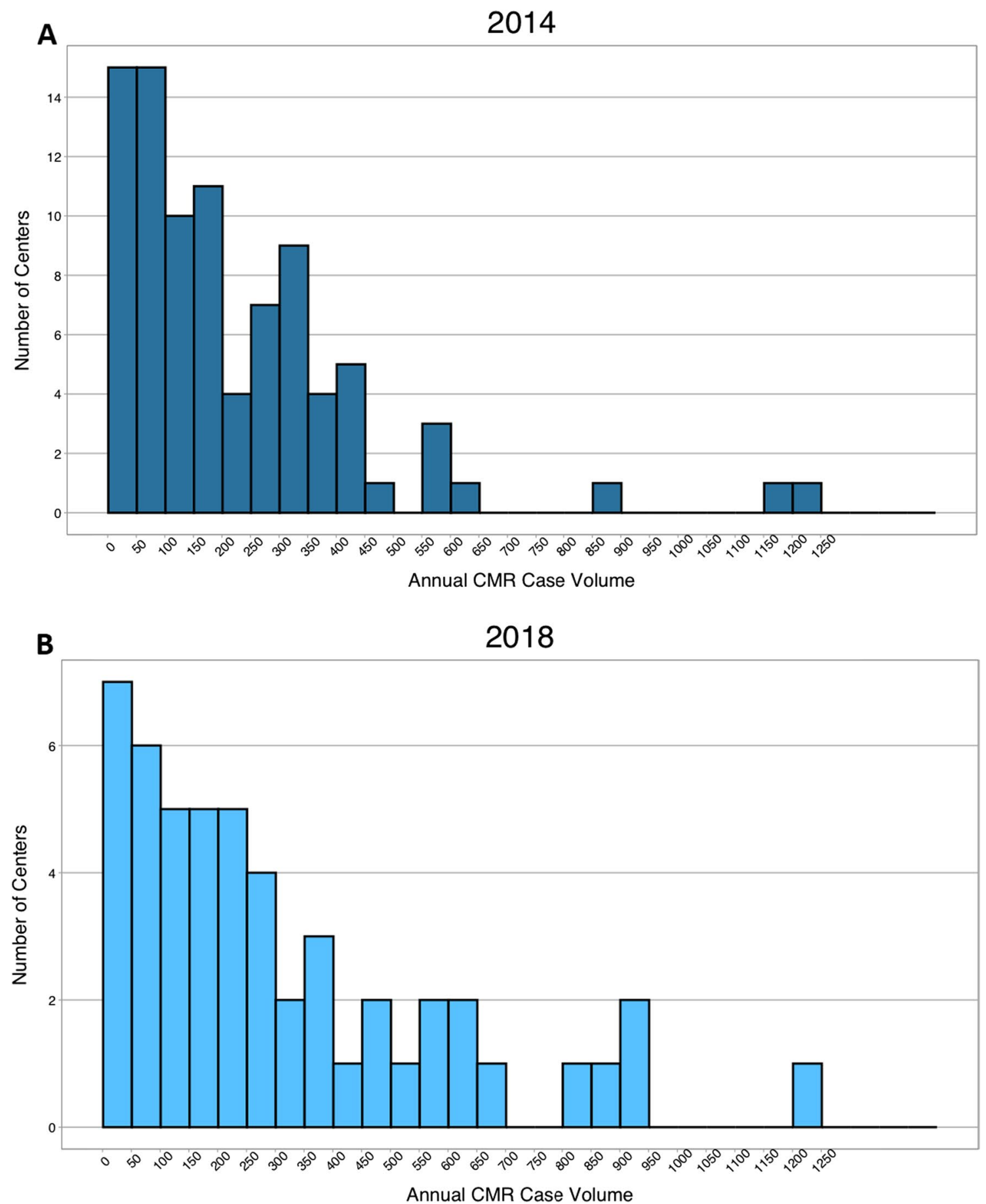

Fig. 2 Annual pediatric and congenital heart disease patient CMR case volume per center in 2014 and 2018

and $1-1 \%$ were dual trained radiologist and cardiologists (Fig. 3). A more detailed breakdown by specialty training of this group is shown in Table 2. The official signer of the CMR reports by specialty is presented in Table 3. Physician training in pediatric/congenital
CMR was provided at $41-43 \%$ of the centers. The median number of technologists per center performing pediatric/congenital CMR examinations was 4-5. The median case volume per technologist per year was 45-43. 


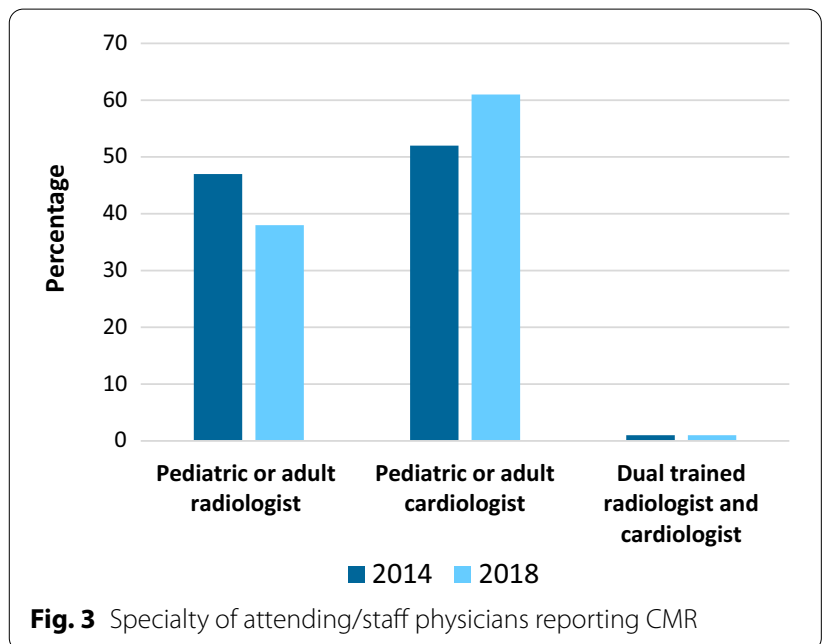

Table 2 Specialty training of attending/staff reporting pediatric/ congenital CMR examinations

\begin{tabular}{lll}
\hline Specialty training & $\mathbf{2 0 1 4}(\%)$ & $\mathbf{2 0 1 8}(\%)$ \\
\hline Pediatric cardiology & 28 & 45 \\
Pediatric radiology & 20 & 19 \\
Adult cardiology & 21 & 12 \\
Adult radiology & 19 & 15 \\
Adult and pediatric cardiology & 3 & 4 \\
Adult and pediatric radiology & 8 & 4 \\
Radiology and cardiology & 1 & 1 \\
\hline
\end{tabular}

\section{Workflow and resources}

CMR examinations were performed 1 day per week at $19-30 \%$ of centers, $2-4$ days per week at $45-43 \%$ of centers, and $\geq 5$ days per week at $29-27 \%$ of centers. The median scanner time allocated for a non-sedated examination was 75-75 min (range, 45-120). Physicians were typically present in the same room as the technologist for $>60 \%$ of the examination time in $91-86 \%$ of centers. The mean time for an attending/staff physician to perform and report a typical CMR examination was 126-130 min.

The initial contour drawing for analysis of ventricular volume and flow measurements was performed by an attending/staff physician only at $37-32 \%$ of centers, a physician trainee only in $9-5 \%$, a technician only in $5-7 \%$, a technologist only in $5-7 \%$, and a combination of these in 44-24\%. An in-house post-processing team (e.g., $3 \mathrm{D}$ laboratory) or third-party company was used in $25 \%$ of centers in 2018; it was not a response option in 2014. For ventricular volume calculation, the software vendor was Siemens (Siemens Healthineers, Erlangen, Germany) at 31-9\%, Medis (Medis Medical Imaging, Leiden, The Netherlands) at 25-26\%, Philips (Philips Healthcare, Best, the Netherlands) at 20-5\%, General Electric (General Electric Healthcare, Chicago, IL, USA) at 11-7\%, cvi42 (Circle Cardiovascular Imaging, Calgary, Alberta, Canada) at 9-34\%, Osirix (Osirix Foundation, Geneva, Switzerland) at 1-2\%, Segment CMR (Medviso, Lund, Sweden) at 1-2\%, Heart Imaging Technologies (Durham, North Carolina, USA) at 0-5\%, TeraRecon (Acton, Massachusetts, USA) at 0-5\%, Arterys (San Francisco, CA, USA) at $0-4 \%$ and other at $2-1 \%$. For blood flow calculation, the software vendor was Siemens at 34-9\%, Philips at $23-7 \%$, Medis at $20-25 \%$, General Electric at $12-5 \%$, cvi42 at $8-34 \%$, Segment CMR at $1-4 \%$, Heart Imaging Technologies at $0-7 \%$, TeraRecon at $0-5 \%$, and other at $2-4 \%$.

\section{Centers responding to both surveys}

A total of 21 centers responded to both surveys. The mean case volume per year increased from 320 in 2014 to 445 in $2018 ; 17$ (81\%) of the centers had an increase in case volume per year. The median number of attending/ staff physicians reporting CMR examinations per center was 4 in both 2014 and 2018. Among the attending/ staff physicians reporting CMR examinations, 62-65\% were pediatric or adult cardiologists and 38-35\% were pediatric or adult radiologists. The median scanner time allocated for a non-sedated examination was $90 \mathrm{~min}$ in both 2014 and 2018. The mean time for an attending/staff

Table 3 Official signer of CMR reports by specialty

\begin{tabular}{|c|c|c|}
\hline Signer & $2014(\%)$ & $2018(\%)$ \\
\hline Only cardiologists officially sign reports & 30 & 34 \\
\hline Only radiologists officially sign reports & 27 & 4.5 \\
\hline $\begin{array}{l}\text { Only one physician signs each report, and this may be either a cardiologist or radiologist ( } 1 \text { report per } \\
\text { patient) }\end{array}$ & 21 & 23 \\
\hline Both radiologists and cardiologists officially sign all reports (2 physicians per report) & 12 & 25 \\
\hline Radiologists and cardiologists sign some studies jointly and some by themselves & 10 & 9 \\
\hline A radiologist and a cardiologist each sign separate reports on the same patient (2 reports per patient) & 0 & 4.5 \\
\hline
\end{tabular}


physician to perform a typical CMR examination including reporting was $143 \mathrm{~min}$ in 2014 and $141 \mathrm{~min}$ in 2018.

\section{Discussion}

This report is the first comprehensive international survey of CMR centers/programs caring for patients with pediatric or congenital heart disease. The survey was voluntary and distributed in 2014 and then again in 2018. Overall, it demonstrated significant variation in program size, case volume, and some practices.

In both survey years, approximately two-thirds of the responding centers were in the United States. This likely overrepresents the United States compared to other countries throughout the world but is reflective of the SCMR membership. Most centers were independent children's hospital, followed by children's hospital within a larger general hospital and then a general hospital where majority of patients are adults. It is unclear how well this distribution reflects all CMR centers worldwide caring for patients with pediatric or congenital heart disease. It seems possible that independent children's hospitals may be more common in the United States than in other countries as a whole, thereby skewing the results. Nearly all centers in the survey also performed surgery on pediatric and congenital heart disease patients. This high proportion raises the possibility that smaller centers and dedicated imaging centers may be underrepresented.

This survey yielded interesting information about CMR imaging techniques in pediatric and congenital heart disease patients. With regard to scanner field strength, the majority of centers used only a $1.5 \mathrm{~T}$ scanner while just $4 \%$ used only a $3 \mathrm{~T}$ scanner; the remainder used both a $1.5 \mathrm{~T}$ and a $3 \mathrm{~T}$ scanner. The more frequent use of $1.5 \mathrm{~T}$ scanners may be a reflection of them being more common or accessible at the survey centers. However, the results, particularly the few centers relying only on a $3 \mathrm{~T}$ scanner, may also indicate a preference for the lower field strength even when both are available. We speculate that this could be related to differences in image quality with banding artifacts from off-resonance effects being more common at 3T. Moreover, metallic implanted devices (e.g., stents, vascular occlusion coils, and prosthetic valves) are relatively common in patients with congenital heart disease and produce more image artifact at higher field strength. Although some cardiac applications such as coronary imaging, myocardial perfusion imaging, and myocardial tagging are likely superior at 3T, the need for these in pediatric and congenital heart disease patients may be less prominent than that in patients with adult-onset conditions. The use of sedation or anesthesia for some CMR examinations was common among the responding centers. Some centers preferred to use general anesthesia over sedation while others had a mixed approach. This variation is likely in part because general anesthesia requires specialized personnel, equipment, and resources [1215] that are not universally available. Lastly, it is notable that in the 2018 survey, macrocyclic GBCAs were more commonly used than linear GBCAs. This likely stems from studies that show a higher likelihood of cerebral gadolinium deposition with linear GBCAs compared to macrocyclic GBCAs [16-18]. Nevertheless, the clinical relevance of these depositions has yet to be determined [19].

This survey demonstrates that CMR in patients with pediatric or congenital heart disease is performed by physicians with a variety of subspecialty certifications; these included adult and pediatric radiology, and adult and pediatric cardiology [20-22]. The proportion of these specialists reported in this survey may not be representative of the field as a whole because of sampling biases. The median case volume per attending/staff physician per year was 54 in 2014 and increased to 86 in 2018, and per technologist per year was 45 in 2014 and 43 in 2018. In comparison to the volumes seen in other cardiac imaging modalities (e.g., echocardiography), these volumes are relatively small.

Our survey data on workflow support the notion that CMR examinations in patients with pediatric or congenital heart disease are time and resource intensive compared to other types of magnetic resonance examinations. The median scanner time allocated for a non-sedated examination was approximately $75 \mathrm{~min}$. The mean time for an attending/staff physician to perform a typical CMR examination including reporting was approximately $130 \mathrm{~min}$. Physicians were typically present in the same room as the technologist for $>60 \%$ of the examination time at nearly all centers. This information may be useful to ensure that appropriate financial and physician work credit is assigned to this type of examination. Although the explanation for the resource utilization was not explicitly assessed in the survey, CMR examinations in patients with pediatric or congenital heart disease may involve time-consuming coaching to elicit patient cooperation, complex anatomy and unexpected findings such that the imaging protocol needs expert supervision and tailoring in real-time, and multiple relevant clinical questions that add to the examination and reporting time. Of note, centers that responded to both surveys had onaverage longer scan slots and interpretation times despite presumably a greater experience and larger volumes than the average in the other groups. While it is unlear if this could be related to adding new sequences, overall this data suggests that experience may not decrease scan times or interpretation times. The survey's results also highlight the need to develop faster scanning techniques 
and automated image analysis to maximize efficiency [23-25].

\section{Limitations}

The generalizability of this survey is limited by potential selection bias (detailed above) and response bias. No comprehensive list of CMR centers/programs caring for patients with pediatric or congenital heart disease is available. Beyond goodwill, the only incentive offered to participate was access to the results as soon as they were collated. Another limitation to this survey was that data from centers are self-reported and were not independently validated. Future surveys should aim for more widespread dissemination and consider offering additional incentives to respond.

\section{Conclusions}

This survey data provides a novel comprehensive view of CMR practice in pediatric and congenital heart disease from centers across the globe. The information is useful for internal benchmarking, identifying unmet needs, addressing practice variation, resource allocation, and developing quality improvement initiatives. It also serves as a foundation for future surveys.

\section{Abbreviations}

4D: 4 Dimensional; CMR: Cardiovascular magnetic resonance; GBCA: Gadolinium-based contrast agents; SCMR: Society for Cardiovascular Magnetic Resonance.

\section{Supplementary Information}

The online version contains supplementary material available at https://doi. org/10.1186/s12968-021-00830-4.

Additional file 1. Pediatric/congenital CMR survey.

\section{Acknowledgements}

SCMR Pediatric and Congenital Heart Disease Section Steering Committee.

\section{Authors' contributions}

All authors were involved in study conception, data analysis, and interpretation of data. All authors read and approved the final manuscript.

\section{Funding}

None.

\section{Availability of data and materials}

The datasets during and/or analyzed during the current study are available from the corresponding author on reasonable request.

\section{Declarations}

Ethics approval and consent to participate

The ethics approval and consent was waived by our IRB.
Consent for publication

Not applicable.

\section{Competing interests}

The authors declare that they have no competing interests.

\section{Peer Review Status}

This article is a publication of the Society of Cardiovascular Magnetic Resonance - it has been endorsed by the Society and assessed by the Editor-inChief prior to publication.

\section{Author details}

${ }^{1}$ Division of Cardiology, Department of Pediatrics, University of Washington School of Medicine and Seattle Children's Hospital, Seattle, WA, USA. ${ }^{2}$ Department of Cardiology, Department of Pediatrics, Boston Children's Hospital, Harvard Medical School, Boston, MA, USA.

Received: 29 October 2021 Accepted: 22 November 2021

Published online: 03 February 2022

References

1. Leiner T, Bogaert J, Friedrich MG, Mohiaddin R, Muthurangu V, Myerson S, et al. SCMR Position Paper (2020) SCMR Position Paper on clinical indications for cardiovascular magnetic resonance. J Cardiovasc Mag Reson Off J Soc Cardiovasc Magn Reson. 2020;22(1):76.

2. Sachdeva R, Valente AM, Armstrong AK, Cook SC, Han BK, Lopez L, et al. ACC/AHA/ASE/HRS/ISACHD/SCAI/SCCT/SCMR/SOPE 2020 Appropriate Use Criteria for Multimodality Imaging During the Follow-Up Care of Patients With Congenital Heart Disease: A Report of the American College of Cardiology Solution Set Oversight Committee and Appropriate Use Criteria Task Force, American Heart Association, American Society of Echocardiography, Heart Rhythm Society, International Society for Adult Congenital Heart Disease, Society for Cardiovascular Angiography and Interventions, Society of Cardiovascular Computed Tomography, Society for Cardiovascular Magnetic Resonance, and Society of Pediatric Echocardiography. J Am Coll Cardiol. 2020;75(6):657-703.

3. Valsangiacomo Buechel ER, Grosse-Wortmann L, Fratz S, Eichhorn J, Sarikouch S, Greil GF, et al. Indications for cardiovascular magnetic resonance in children with congenital and acquired heart disease: an expert consensus paper of the Imaging Working Group of the AEPC and the Cardiovascular Magnetic Resonance Section of the EACVI. Eur Heart J Cardiovasc Imag. 2015;16(3):281-97.

4. Lai WW, Srivastava S, Cohen MS, Frommelt PC, Allada V. Pediatric echocardiography laboratory organization and clinical productivity. Journal of the American Society of Echocardiography: official publication of the American Society of Echocardiography. 2013;26(10):1180-6.

5. Srivastava S, Allada V, Younoszai A, Lopez L, Soriano BD, Fleishman CE, et al. Determinants of pediatric echocardiography laboratory productivity: analysis from the second survey of the American society of echocardiography committee on echocardiography laboratory productivity. J Am Soc Echocardiogr Off Publ Am Soc Echocardiogr. 2016;29(10):1009-15.

6. Srivastava S, Lopez L. ACC/AHA/ASE/HRS/ISACHD/SCAI/SCCT/SCMR/ SOPE 2020 Appropriate Use Criteria for Multimodality Imaging During the Follow-Up Care of Patients With Congenital Heart Disease: A Report of the American College of Cardiology Solution Set Oversight Committee and Appropriate Use Criteria Task Force, American Heart Association, American Society of Echocardiography, Heart Rhythm Society, International Society for Adult Congenital Heart Disease, Society for Cardiovascular Angiography and Interventions, Society of Cardiovascular Computed Tomography, Society for Cardiovascular Magnetic Resonance, and Society of Pediatric Echocardiography. J Am Soc Echocardiogr Off Publ Am Soc Echocardiogr. 2013;26(12):A18

7. Soriano BD, Fleishman CE, Van Hoever AM, Wright B, Printz B, Tacy TA, et al. Determinants of physician, sonographer, and laboratory productivity: analysis of the third survey from the American society of echocardiography committee on pediatric echocardiography laboratory productivity. J Am Soc Echocardiogr Off Publ Am Soc Echocardiogr. 2018;31(9):976-82.

8. Camarda JA, Patel A, Carr MR, Young LT. Practice variations in pediatric echocardiography laboratories. Pediatr Cardiol. 2019;40(3):537-45. 
9. Rimsza ME, Ruch-Ross HS, Clemens CJ, Moskowitz WB, Mulvey HJ. Workforce trends and analysis of selected pediatric subspecialties in the United States. Acad Pediatr. 2018;18(7):805-12.

10. Stoddard JJ, Cull WL, Jewett EA, Brotherton SE, Mulvey HJ, Alden ER. Providing pediatric subspecialty care: a workforce analysis. AAP Committee on Pediatric Workforce Subcommittee on Subspecialty Workforce. Pediatrics. 2000;106(6):1325-33.

11. MacKay EJ, Groeneveld PW, Fleisher LA, Desai ND, Gutsche JT, Augoustides JG, et al. Practice pattern variation in the use of transesophageal echocardiography for open valve cardiac surgery. J Cardiothorac Vasc Anesth. 2019;33(1):118-33.

12. Dorfman AL, Odegard KC, Powell AJ, Laussen PC, Geva T. Risk factors for adverse events during cardiovascular magnetic resonance in congenital heart disease. J Cardiovasc Magn Reson Off J Soc Cardiovasc Magn Reson. 2007;9(5):793-8.

13. Fogel MA, Weinberg PM, Parave E, Harris C, Montenegro L, Harris MA, et al. Deep sedation for cardiac magnetic resonance imaging: a comparison with cardiac anesthesia. J Pediatr. 2008;152(4):534 9.e1.

14. Odegard KC, DiNardo JA, Tsai-Goodman B, Powell AJ, Geva T, Laussen PC. Anaesthesia considerations for cardiac MRI in infants and small children. Paediatr Anaesth. 2004;14(6):471-6.

15. Osborn IP. Magnetic resonance imaging anesthesia: new challenges and techniques. Curr Opin Anaesthesiol. 2002;15(4):443-8.

16. Radbruch A, Richter H, Fingerhut S, Martin LF, Xia A, Henze N, et al. Gadolinium deposition in the brain in a large animal model: comparison of linear and macrocyclic gadolinium-based contrast agents. Investig Radiol. 2019;54(9):531-6

17. Kanda T, Osawa M, Oba H, Toyoda K, Kotoku J, Haruyama T, et al. High signal intensity in dentate nucleus on unenhanced T1-weighted MR images: association with linear versus macrocyclic gadolinium chelate administration. Radiology. 2015;275(3):803-9.

18. McDonald RJ, McDonald JS, Dai D, Schroeder D, Jentoft ME, Murray DL, et al. Comparison of gadolinium concentrations within multiple rat organs after intravenous administration of linear versus macrocyclic gadolinium chelates. Radiology. 2017;285(2):536-45.

19. Chehabeddine L, Al Saleh T, Baalbaki M, Saleh E, Khoury SJ, Hannoun S. Cumulative administrations of gadolinium-based contrast agents: risks of accumulation and toxicity of linear vs macrocyclic agents. Crit Rev Toxicol. 2019;49(3):262-79.

20. Atalay MK. Establishing a cardiac MRI program: problems, pitfalls, expectations. J Am Coll Radiol JACR. 2005;2(9):740-8.

21. Kinney JB, Rovira MJ, Sahn DJ, Lupinetti FM, Gilman MD, Wexler L. MRI of congenital heart disease: a paradigm of collaboration. new suggestions for a team approach from Madigan Army Medical Center. J Cardiovasc Magn Reson Off J Soc Cardiovasc Magn Reson. 2002;4(3):369-72.

22. O'Regan DP, Schmitz SA. Establishing a clinical cardiac MRI service. Clin Radiol. 2006;61(3):211-24.

23. Budai A, Suhai FI, Csorba K, Toth A, Szabo L, Vago H, et al. Fully automatic segmentation of right and left ventricle on short-axis cardiac MRl images. Comput Med Imag Graph Off J Compu Med Imag Soc. 2020;85:101786.

24. Pace DF, Dalca AV, Geva T, Powell AJ, Moghari MH, Golland P. Interactive Whole-Heart Segmentation in Congenital Heart Disease. Medical image computing and computer-assisted intervention: MICCAI International Conference on Medical Image Computing and Computer-Assisted Intervention. 2015:9351:80-8.

25. Steeden JA, Quail M, Gotschy A, Mortensen KH, Hauptmann A, Arridge $S$, et al. Rapid whole-heart CMR with single volume super-resolution. J Cardiovasc Magn Reson Off J Soc Cardiovasc Magn Reson. 2020;22(1):56.

\section{Publisher's Note}

Springer Nature remains neutral with regard to jurisdictional claims in published maps and institutional affiliations.

Ready to submit your research? Choose BMC and benefit from:

- fast, convenient online submission

- thorough peer review by experienced researchers in your field

- rapid publication on acceptance

- support for research data, including large and complex data types

- gold Open Access which fosters wider collaboration and increased citations

- maximum visibility for your research: over $100 \mathrm{M}$ website views per year

At BMC, research is always in progress.

Learn more biomedcentral.com/submissions 